\title{
Effects of Probiotics and Vitamin B Supplementation on IFN-Y and IL-12 Levels During Intensive Phase Treatment of Tuberculosis
}

\author{
Budi Suprapti ${ }^{1,3} *$, Suharjono ${ }^{1}$, Rahmawati Raising ${ }^{1}$, Yulistiani ${ }^{1,3}$, Zamrotul \\ Izzah $^{1,3}$, Wenny Putri Nilamsari ${ }^{1}$, Prastuti Asta Wulaningrum ${ }^{2}$, Arief Bachtiar ${ }^{2}$
}

${ }^{1}$ Department of Clinical Pharmacy, Universitas Airlangga, Campus B, Dharmawangsa Dalam Selatan, Surabaya, East Java Province, Indonesia 60286 2Department of Pulmonology and Respiratory Medicine, Universitas Airlangga Teaching Hospital, Surabaya,

${ }^{3}$ Department of Pharmacy, Universitas Airlangga Teaching Hospital, Surabaya.

Submitted: 09-03-2018

Revised: $16-04-2018$

Accepted: 28-05-2018

*Corresponding author Budi Suprapti

Email: budiprapti@yahoo.co.id

\begin{abstract}
Tuberculosis (TB) is an acute infectious disease that primarily affects the lungs. Probiotics supplementation can increase the number and activity of NK cell in peripheral blood by modulation of interleukin-12 (IL-12), thus increasing interfenon- $\gamma$ (IFN- $\gamma$ ) production by T-helper cells type 1 (Th1) response. Vitamin $B_{1}$ acts on macrophages and affects neutrophil motility. Vitamin $B_{6}$ is associated with the release of cytokines and the responsiveness of NK cells, while vitamin $B_{12}$ affects to lymphocytes, Tcell proliferation, $\mathrm{CD}^{+}$ratios, and NK cell activity. This study aim to analyze the effects of probiotics and vitamin $B_{1}, B_{6}, B_{12}$ supplementation on IFN- $\gamma$ and IL-12 levels during intensive phase of antituberculosis treatment. The study was pre-post test randomised control by time series. The control group was TB patients with standard therapy of antituberculosis and vitamin B6, while the intervention group was TB patients receiving therapy plus once daily probiotics and vitamin $B_{1}$, $B_{6}, B_{12}$ supplementation during the intensive phase. Blood samples were withdrawn at baseline, one month, and two months after therapy to measure plasma IFN- $\gamma$ and IL-12 levels using the ELISA method. Twenty two patients were divided equally into two groups. There was a tendency to greater increase of IFN- $y$ in the first month of the intervention group, followed by a significant decline after two-month therapy $(p<0.05)$. In both groups there was a rise in IL-12 levels after one month followed by a decrease in the second month $(p>0.05)$. However, the percentage was higher in the supplementation group. Addition of probiotics and vitamins $B_{1}, B_{6}$, $B_{12}$ could improve immune response through IL-12 and IFN-Y modulation during intensive phase therapy.
\end{abstract}

Keywords: Interleukin-12, Interferon- $\gamma$, Probiotics, Tuberculosis, Vitamin B

\section{INTRODUCTION}

Tuberculosis (TB) is an acute infectious disease caused by Mycobacterium tuberculosis (Mtb). TB can be transmitted from one individual to another through airbone droplets. Globally, TB is the leading cause of death from a single infectious agent, killing approximately 1.67 million persons in 2016. At least one quarter of persons worldwide, approximately 1.7 billion people, are infected with Mtb. Among these infected persons, approximately $10 \%$ or 170 million persons globally, will be expected to develop TB during their lifetimes (WHO, 2018). According to the recent report, there are new high burden countries lists for the period of 2016-2020 (TB, Multidrug- resistant $\mathrm{TB}$ (MDR-TB) and TB/ HIV), and Indonesia is among the 20 top countries with the incident of 10.000 per year for TB, and 1,000 per year for TB/HIV (WHO, 2017).

The body's defense system for the intracellular bacterial infections which have important role are macrophages and Th1 cells. Those act as a specific mediator in destroying Mtb. Fagocytic cells that influx bacteria and become apoptosis will be uptaken by lung dendritic cell then transported to lymphe. This is the stimulate adaptive immune phase, T-helper tipe 1 (Th1) stimulates the cytokine secretion (Etna, 2014). Cytokines that have important contribution to TB infection include IFN- $\gamma$, TNF- $\alpha$, IL-12, IL-17, IL-10, and IL-6. 
In turn cytokine will stimulate neutrophils and activate macrophages, form granulomas, and form antimicrobial agents such as oxygen and nitrogen reactive to inhibit Mtb (Adrian et al, 2015).

Probiotics can modulate the immune system through the activity of epithel cells and immune cell receptors. In respiratory tract infections, there is an increase in the activity of fagocytes from alveolar macrophages after the administration of probiotics, thus increasing the activity of NK cells in the IFN- $\gamma$ production (Forsythe, et al., 2013; Mortaz, et al., 2013).

Some vitamins can affect to body's immunity, including cell-mediated immunity, humoral immunity, and phagocytic activity of leucocytes. Vitamin $B_{1}$ has an action in macrophages and affects neutrophil motility. Vitamin $\mathrm{B}_{6}$ can release cytokines or chemokines and has responsibility to the responsiveness of NK cells. In addition, vitamin $B_{12}$ increases lymphocytes as well as improves the abnormal CD4/CD8 ratio and NK cell activity (Shetty $e t$ al, 2010; Spinas et al, 2015).

The use of probiotics and vitamin $B_{1}, B_{6}$, $\mathrm{B}_{12}$ supplementation in tuberculosis patient has not yet been determined. Therefore, this study was aimed to analyze the effects of those supplementation on IFN- $\gamma$ and IL-12 levels in tuberculosis patients.

\section{MATERIALS AND METHODS}

The study protocol was ethically approved by the Ethics and Law Committee of Airlangga University Hospital on August 2016. The study was pre-post test randomised control by time series applied to the naïve and newly-diagnosed TB patients. The first group consisted of patients with the first-line standard therapy of oral antituberculosis and vitamin $\mathrm{B}_{6}$ (control), whereas the second group was patients receiving therapy and supplementation of probiotics and vitamin $\mathrm{B}_{1}, \mathrm{~B}_{6}, \mathrm{~B}_{12}$ (intervention). Both standard therapy and supplementation were administered once daily during the intensive phase of treatment. The study was conducted at the Universitas Airlangga Hospital and Primary Healthcare Centers in Surabaya within period of December 2016 and February 2017. The inclusion criteria were patients aged $18-65$ years, diagnosed with active TB, started first-line antituberculosis treatment for the intensive phase, had no previous history of probiotics and vitamin $\mathrm{B}_{1}, \mathrm{~B}_{6}, \mathrm{~B}_{12}$ before enrollment, and signed the informed consent. The exclusion criteria were patients with HIV co-infection, pregnancy, lactation, diabetes mellitus, pneumonia, and current administration of corticosteroids or other immunosuppressants.

Multistrain probiotics (Lactobaccilus acidopbilu, L. casei, L. rhamnosus, L. bulgaricus, Bifidobacterium breve, B. longum, Streptococcus thermophilus), vitamin $\mathrm{B}_{1} 100 \mathrm{mg}, \mathrm{B}_{6} 100 \mathrm{mg}, \mathrm{B}_{12}$ $5.000 \mathrm{mcg}$ were administered once daily in the intervention (second) group. Blood samples were withdrawn at baseline, after one month, and two months of intensive therapy for further plasma IFN- $\gamma$ and IL-12 assay using the ELISA method. The t-test analysis was performed to evaluate the effects of probiotics and vitamin B supplementation.

\section{RESULTS AND DISCUSSION}

The characteristics of patients (Table I) Data were distributed normally, and no significant differences were found between the two groups ( $\mathrm{p}>0.05)$.

The Figure 1A and $2 \mathrm{~A}$ showed the plasma IFN- $\gamma$ levels in both groups. The levels increased from $32.735 \mathrm{pg} / \mathrm{mL}$ before therapy to $40.325 \mathrm{pg} / \mathrm{mL} \quad(p=0.445)$ after one month followed by a decrease to $39.640 \mathrm{pg} / \mathrm{mL}$ $(p=0.859)$ in the second month. Whereas, plasma IFN- $\gamma$ levels in the intervention group rose from $73.767 \mathrm{pg} / \mathrm{mL}$ before therapy to $97.768 \mathrm{pg} / \mathrm{mL}(p=0.241)$ in the first month and next significantly declined to $43.472 \mathrm{pg} / \mathrm{mL}$ $(p=0.007)$ at the end of two-month of intensive therapy.

Similarly, figures $1 \mathrm{~B}$ and $2 \mathrm{~B}$ revealed that plasma IL-12 levels in the control group elevated from $2.663 \mathrm{pg} / \mathrm{mL}$ before therapy to $3.303 \mathrm{pg} / \mathrm{mL}(p=0.091)$ in the first month and diminished to $2.550 \mathrm{pg} / \mathrm{mL}(\phi=0.155)$ after two months of therapy. In addition, plasma IL-12 levels of the intervention group increased from $3.173 \mathrm{pg} / \mathrm{mL}$ before therapy to $4.168 \mathrm{pg} / \mathrm{mL}(p=0.061)$ after one and decreased significantly to $2.567 \mathrm{pg} / \mathrm{mL}(p=0.003)$ in the second month. 
Table I. Patients demography

\begin{tabular}{|c|c|c|c|}
\hline Parameter & Control group N (\%) & Intervention group $\mathbf{N}(\%)$ & $p$ value* \\
\hline Total & 11 & 11 & \\
\hline \multicolumn{4}{|l|}{ Gender } \\
\hline Male & $4(36.4)$ & $4(36.4)$ & \multirow{2}{*}{1.000} \\
\hline Female & $7(63.6)$ & $7(63.6)$ & \\
\hline \multicolumn{4}{|l|}{ Age (years) } \\
\hline $18-24$ & $2(18.2)$ & $2(18.2)$ & \multirow{5}{*}{0.389} \\
\hline $25-34$ & $2(18.2)$ & $2(18.2)$ & \\
\hline $35-44$ & $2(18.2)$ & $5(45.4)$ & \\
\hline $45-54$ & $4(36.3)$ & $1(9.1)$ & \\
\hline 55-65 & $1(9.1)$ & $1(9.1)$ & \\
\hline \multicolumn{4}{|l|}{ AFB smear result } \\
\hline Positive & $7(63.6)$ & $6(54.5)$ & \multirow{2}{*}{1.000} \\
\hline Negative & $4(36.4)$ & $5(45.5)$ & \\
\hline \multicolumn{4}{|c|}{ Duration of symptoms (cough, night sweats) } \\
\hline$\geq 1$ month & $9(81.8)$ & $11(100.0)$ & \multirow{2}{*}{0.065} \\
\hline$<1$ month & $2(18.2)$ & $0(0)$ & \\
\hline \multicolumn{4}{|l|}{ Smoking } \\
\hline Yes & $1(9.1)$ & $1(9.1)$ & \multirow{2}{*}{1.000} \\
\hline No & $10(90.9)$ & $10(90.9)$ & \\
\hline \multicolumn{4}{|l|}{ Co-morbidities } \\
\hline Asthma & $0(0)$ & $1(9.1)$ & \multirow{4}{*}{0.413} \\
\hline Hyperthyroid & $0(0)$ & $1(9.1)$ & \\
\hline Ulcer & $1(9.1)$ & $2(18.2)$ & \\
\hline None & $10(90.9)$ & $7(63.6)$ & \\
\hline \multicolumn{4}{|l|}{ Diagnosed TB } \\
\hline Pulmonary & $7(63.6)$ & $10(90.9)$ & \multirow{2}{*}{0.311} \\
\hline Extrapulmonary & $4(36.4)$ & $1(9.1)$ & \\
\hline
\end{tabular}

* calculated by chi-square test for categorical variables

This study recruited 22 newly-diagnosed TB patients and were divided equally into each group. The diagnosis was primarily based on the Acid-Fast Bacilli (AFB) smear results or chest $\mathrm{x}$-ray, in addition to clinical features such as cough and night sweats. Although most patients experienced pulmonary TB rather than extrapulmonary type, the process of body immune system response to Mtb for both conditions is similar (Adrian et al, 2015). All patients were administered the first-line antituberculosis therapy as standard therapy according to the current WHO guideline (WHO, 2017).

Probiotics are microorganisms alive that given in sufficient quantities to provide benefits. They have shown to increase the amount and activity of cytotoxic NK cells in peripheral blood, with IL-12 immunomodulation increasing the expression of NK cell receptors. Thus, it can be concluded that probiotics are capable of increasing Th1 responses (Kechagia, et al, 2013; Nanno, et al, 2014). For example, the L. pentosus strain significantly increased the activity of $\mathrm{NK}$ cells in the spleen through IL-12. Increased levels of IL-12 in dendritic cells cause NK stimulation, thus increasing IFN-production (Forsythe, 2013; Mortaz, et al, 2013). Previous studies have shown that combination of multistrain probiotics provide better results because they produce synergistic effects among strains to inhibit more pathogens. Another study also revealed that the use of probiotics is useful in reducing the incidence of respiratory tract infections (Chapman et al, 2011; Chapman et al, 2012). 

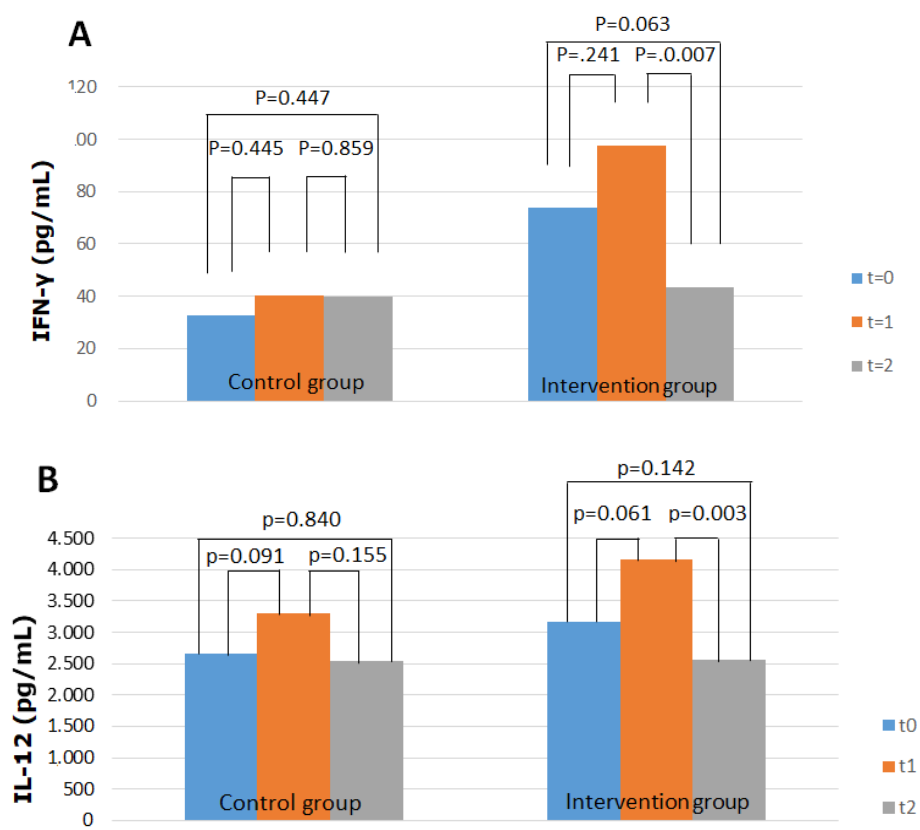

Figure 1. Changes in plasma IFN- $\gamma$ (A) and IL-12 (B) levels in the control and intervention groups before therapy ( $\mathrm{t} 0$ ), after one month ( $\mathrm{t} 1)$, and two months of intensive phase therapy ( $\mathrm{t} 2)$.
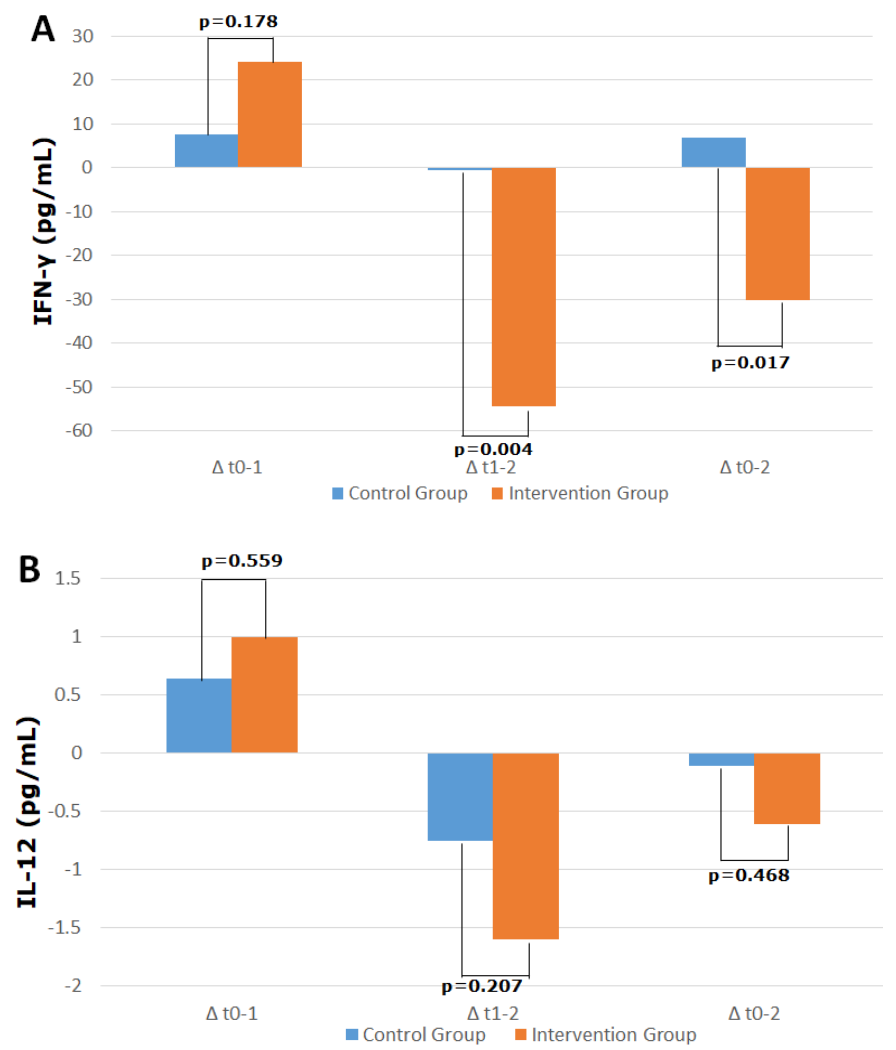

Figure 2. Differences within a month between IFN- $\gamma$ and IL-12 levels in in the control and intervention groups during the intensive phase therapy 
Vitamins also affect the body's immunity, such as vitamin $B_{1}$ which works on macrophages and influences the neutrophil motility, vitamin $\mathrm{B}_{6}$ is associated with the release of cytokines or chemokine's and responsiveness of $\mathrm{NK}$ cells, and vitamin $\mathrm{B}_{12}$ influences lymphocytes, $\mathrm{T}$ cell proliferation, CD4/CD8 and NK cells activity (Shetty et al, 2010; Spinas et al, 2015).

Furthermore, combination of multistrain probiotics and vitamin B supplementation provides enhanced immunomodulation activities during the intensive phase therapy as shown by the trends of increase in the first month and decrease at the end of intensive therapy between IFN- $\gamma$ and IL-12 levels in the intervention group compared to the control group. Clifford et al (2015) reported that there was an increase in IFN- $\gamma$ levels in active TB treatment. When the host is infected by Mtb, there will be bacterial influx by phagocytic cells, especially alveolar macrophages and neutrophil, which in turn induce apoptosis. The apototic cells will be captured by pulmonary dendritic cells that act as antigens presenting cell (APC) to be carried into lymph with the help of IL-12 and chemokines. Dendritic cells also produce IL-12 to support differentiation of naive T cells into helper T cells (Th1, Th2, TTh9, Th 17, Th 22 and $\mathrm{T}$ regulator cells). In the lung, $\mathrm{T}$ cells produce various cytokines such as TNF- $\alpha$ and IFN- $\gamma$ by Th1 cells (O'Garra et al, 2013). In early infection phase and first month of antituberculosis therapy, probiotics and vitamin $\mathrm{B}$ supplementation will enhance IFN- $\gamma$ production, but further the IFN- $\gamma$ level will gradually decrease along with the decrease of inflammation process at the end of intensive treatment (Abul et al, 2016).

Indeed, the levels of IFN- $\gamma$ were higher in the first month of the intervention group compared to the control. This suggested that the supplementation of probiotics and vitamin $\mathrm{B}_{1}, \mathrm{~B}_{6}, \mathrm{~B}_{12}$ plays a role in the modulation of IFN- $\gamma$ secretion in response to Mtb infection. Increased IFN- $\gamma$ levels in the first month may enhance bacteria eradication, as the result the bacteria in the lung or extrapulmonary sites will decrease resulting reduced systemic inflammation. Therefore, at the end of intensive therapy the levels of IFN- $\gamma$ were diminished as shown by a significant reduction in the intervention group. Nevertheless, Devici et al (2005) stated that there was a significant increase in IFN- $\gamma$ levels in the second month and then decreased in subsequent months.

Interestingly, the similar trends also applied to the IL-12 levels. They increased in the first month and then decreased in the second month of therapy either in control or intervention groups. However, the net differences showed greater in the intervention group rather than in the control. IL-12 supports Th1 cell defferention whose secretes IFN- $\gamma$, and then IFN- $\gamma$ will stimulate NK cell to produce more IFN- $\gamma$ (Forsythe, 2011). Sai Priya et al (2009) revealed a decrease in IL-12 response during treatment. This suggested that supplementation may help increase levels of IL-12 in the first month, regulate the balance of T-cell responses and stimulate NK cells in the spleen through IL-12 and increase production IFN- $\gamma$ (Spinas et al, 2015). IFN- $\gamma$ will in turn help to eradicate the bacteria. Reduced levels of IL-12 were aligned with the levels of IFN- $\gamma$. At the end of intensive therapy, the number of active Mtb has decreased, thus reducing the levels of IFN- $\gamma$ and IL-12 levels.

Last, this study was conducted in limited number of patients, so the results cannot be directly generalized to greater population. Therefore, multi-center study with more subject is needed.

\section{CONCLUSIONS}

Supplementation of once-daily multistrain probiotics and vitamin $\mathrm{B}_{1}, \mathrm{~B}_{6}$ and $\mathrm{B}_{12}$ could improve immune system through IFN- $\gamma$ and IL-12 modulation,-increase plasma levels of IFN- $\gamma$ and IL-12 in early phase to help speed up Mtb eradication during the intensive phase of tuberculosis treatment.

\section{ACKNOWLEDGMENTS}

We thank the Primary Healthcare Centers in Surabaya (Puskesmas Ngagel, Sawah Pulo, Sidotopo, Sidotopo Wetan, Tanah Kali Kedinding, dan Mojo) and Universitas Airlangga Hospital. This study was a part of project entitled "Effectivity and Safety of Probiotics and Vitamin B Supplementation in 
Tuberculosis Therapy" and funded by the Ministry of Research, Technology, and Higher Education of Indonesian in 2016.

\section{REFERENCES}

Abul K., Abbas, Andrew HH., Lichtman SP. 2016, 'Basic Immunology : Functions and Disorders of the Immune System'. Elsevier Inc. Ed.5. pp 27-52

Adrian TBR., Montiel JL., Fernandez G., Valecillo A. 2015. "Role of Cytokines and other Factors Involved in the Mycobacterium Tuberculosis Infection". World Journal of Immunology. Vol 5 (1). pp $16-50$

Chapman CMC., Gibson GR Rowland I. 2011. "Health Benefits of Probiotics : Are Mixture More Effective than Single Strains ?" European Journal of Nutrition. 50(1). 1-17.

Chapman CMC., Gibson GR., Rowland I. 2012. "In Vitro Evaluation of Single- and Multi-Strain Probiotics : Inter-Species Inhibition Between Probiotic Strains, and Inhibition of Pathogens". Anaerobe. 18. $405-413$.

Clifford V., Zufferey C., Street A., Denholm J., Tebruegge M., Curtis N., 2015. "Cytokines for monitoring antituberculous therapy: A systematic review". Journal Tuberculosis. Vol 95 (3). pp 217-228

Deveci F., Akbulut HH., Turgut T., Muz HM. 2005. "Changes in Serum Cytokine Levels in Active Tuberculosis With Treatment". Mediators of Inflammmation. 5. 256-262.

Etna MP., Giacomini E., Severa M., Coccia EM, 2014. Pro- and Anti-Inflammatory Cytokines in TB: A Two-Edged Sword in TB Pathogenesis. Seminars in Immunology, 26(6): 543-51
Forsythe P. 2013. "Probiotics and Lung Immune Responses". American Thoracic Society. 11 (1). 33-37.

Kechagia M., Basoulis D., Konstntopoulou S., Dimitriadi D., Gyftopoulou, K., Skarmoutsou N., Fakiri, EM. 2013. "Health Benefits of Probiotics : A Review". Hindawi Publisbing Corporation, Article ID 481651.

Mortaz E., Adcock IM., Folkerts G., Barnes PJ., Vos, AP., Garssen J. 2013. "Probiotics in the Management of Lung Diseases". Mediators of Inflammation. 1-10.

Nanno M., Matsumoto S., Shida K. 2014. Chapter 2 : Modulation of Mucosal Immune System by Probiotics : Postulated Mechnisms. In : Kitazawa, H., Villena, J., and Alvarez, S. (Eds.). Probiotics : Immunobiotics and Immunogenics. Boca Raton : Taylor \& Francis Group, LLC, pp. $12-35$.

O'Garra A., Redford PS., McNab FW., Bloom CI., Wilkinson RJ., Berry, M.P.R. 2013. "The Immune Response in Tuberculosis". The Annual Review of Immunology. Vol 31. pp 475-527.

Shetty P. 2010. "Nutrition, Immunity, and Infection". Cambridge University Press.

Spinas E., Saggini A., Kristas SK., Cerulli G., Caraffa A., Antinolfi P., Pantalone A., Frydas A., Tei M., Speziali A., Saggini, R., Pandolfi F., Conti P. 2015. "Crosstalk between Vitamin B and Immunity". Journal of Biological Regulators and Homeostatic Agents. 29 (2). 283-288.

World Health Organization (WHO), 2018. "Global Report on Tuberculosis report vaccines 2018.

World Health Organization (WHO), 2017. "Global Report on Tuberculosis report 2017 